16 Cummings SR, Nevitt MC, Browner WS, Stone K, Fox KM, Ensrud KE, et al. Risk factors for hip fracture in white women. The study of osteoporotic fractures research group. $N$ Engl J Med 1995;332:767-73.

17 Black DM, Palermo L, Nevitt MC, Genant HK, Epstein R, San Valentin $\mathrm{R}$, et al. Comparison of methods for defining prevalent vertebral fractures: the study of osteoporotic fractures. J Bone Miner Res 1995;10: 890-902.

18 Bauer DC, Browner WS, Cauley JA, Orwoll ES, Scott JC, Black DM, et al. Factors associated with appendicular bone mass in older women. The study of osteoporotic fractures research group. Ann Intern Med 1993;118:657-65.

19 Orwoll ES, Bauer DC, Vogt TM, Fox KM. Axial bone mass in older women. Study of osteoporotic fractures research group. Ann Intern Med $1996 ; 124: 187-96$

20 Leone NC, Stevenson CA, Hilbish TF, Sosman MC. A roentgenologic study of human population exposed to high-fluoride domestic water (a 10-year study). In: McClure FJ, ed. Fluoride drinking waters. Bethesda, MD: National Institute of Dental Research, 1962 (DHEW Publ No (PHS)62-825).

21 Bernstein DS, Sadowsky N, Hegsted DM, Guri D, Stare FJ. Prevalence of osteoporosis in high- and low-fluoride areas in North Dakota. JAMA 1966;198:499-504

22 Ansell BM, Lawrence JS. Fluoridation and the rheumatic diseases. A comparison of rheumatism in Watford and Leigh. Ann Rheum Dis $1966 ; 25: 67-75$.
23 Kroger H, Alhava E, Honkanen R, Tuppurainen M, Saarikoski S. The effect of fluoridated drinking water on axial bone mineral density-a population-based study. Bone Miner 1994;27:33-41.

24 Hillier S, Cooper C, Killingray S, Russell G, Hughes H, Coggon D. Fluoride in drinking water and risk of hip fracture in the UK: a case-control study. Lancet 2000;335:265-9.

25 Ad-Hoc Subcommittee on Fluoride. Review of fluoride benefits and risks. Bethesda, MD: Public Health Service, Department of Health and Human Services, 1991:17.

26 Whitford GM. The metabolism and toxicity of fluoride. Monogr Oral Sci 1996;16(2):1-153.

27 Farley JR, Tarbaux N, Hall S, Baylink DJ. Evidence that fluoride-stimulated 3[H]-thymidine incorporation in embryonic chick calvarial cell cultures is dependent on the presence of a bone cell mitogen, sensitive to changes is depend in the phosphate concentration, a

28 Dabeka RW, McKenzie AD. Survey of lead, cadmium, fluoride, nickel, and cobalt in food composites and estimation of dietary intakes of these elements by Canadians in 1986-1988. J AOAC Int 1995;78:897-909.

29 Lahti SM, Uusitalo U, Feskens E, Haw U, Tuomilehto J, Luoma H. Fluoride and sugar intake among adults and youth in Mauritius: preliminary results. Adv Dent Res 1995;9:21-5.

30 Silbergeld EK, Davis DL. Role of biomarkers in identifying and understanding environmentally induced disease. Clin Chem 1994;40:1363-7.

(Accepted 5 July 2000)

\title{
Audit of oxygen prescribing before and after the introduction of a prescription chart
}

\author{
M E Dodd, F Kellet, A Davis, J C G Simpson, A K Webb, C S Haworth, R McL Niven
}

North West Lung

Centre, South

Manchester

University Hospitals

Trust, Manchester

M23 9LT

M E Dodd

specialist

physiotherapy

clinician

F Kellet

senior physiotherapist

A Davis

senior physiotherapist

A K Webb

consultant physician

C S Haworth

research fellow

R McL Niven

consultant physician

Stepping Hill

Hospital, Poplar

Grove, Stockport

SK2 7JE

J C G Simpson

senior registrar

Correspondence to:

M E Dodd

doddmary@

hotmail.com

BMJ 2000;321:864-5
Oxygen, used to treat hypoxaemia, may be lethal and should therefore be considered a drug and be prescribed. ${ }^{1}$ It is, however, recognised that oxygen is poorly prescribed by doctors. ${ }^{2}$ To ensure the safe and effective delivery of oxygen the prescription should include the flow rate, the concentration, the delivery device, the duration, and the method for monitoring treatment. ${ }^{2}$ We audited the prescription of oxygen to inpatients by doctors before and after the introduction of a specific prescription chart.

\section{Participants, methods, and results}

Junior doctors at the North West Lung Centre are given two lectures on practical aspects of oxygen delivery and prescribing at the beginning of their one year's rotation in respiratory medicine. In 1997 and 1998 the doctors were informed that an audit of their prescribing practice would take place some time during the next year. The outcome measures of the audit were whether the oxygen was prescribed and whether the prescription was accurate-that is, that the audit matched patient use in relation to the delivery device and that the flow rate and concentration were appropriate to that device.

The audit was conducted on three respiratory wards over three months. FK and AD identified all patients receiving oxygen within 24 hours of admission, and they recorded the device, oxygen concentration, and flow rate appropriate to the device for each patient. They consulted a drug Kardex for a prescription of the proposed oxygen treatment. If a prescription was present they recorded the device, concentration, and flow rate. After the first audit, a specific prescription chart for oxygen was developed to encompass all the oxygen delivery systems used on the wards (figure). The methodology for the second audit was identical to that of the first, with the exception that both the chart and the drug Kardex were examined for the prescription. The $\chi^{2}$ test was used to analyse the prescription of oxygen before and after the introduction of the chart.

Overall, 115 patients were identified as receiving oxygen in the first audit and 121 in the second. In the first audit oxygen was prescribed for 63 of the 115 $(55 \%)$ patients. After the chart was introduced the number of oxygen treatments prescribed increased to 110 of $121(91 \%)$ patients $(\mathrm{P}<0.001)$. The prescription was accurate for eight $(7 \%)$ patients in the first audit and $93(77 \%)$ in the second. The accuracy of prescription was $94 \%$ (73 of 78 patients) with the chart and $63 \%$ (20 of 32) with the drug Kardex.

\section{Comment}

Our first audit showed that oxygen was infrequently well prescribed, as previously described. ${ }^{23}$ Junior doctors poorly understand the effects and dangers of oxygen, and lectures alone were insufficient to ensure safe and effective practice. ${ }^{4}$ The prescription chart for oxygen listed the delivery devices, guided the doctor to prescribe the appropriate concentration and flow rate, and provided additional notes for the specific indications of each device.

The most common omission from the prescriptions was flow rate. The flow rate of fixed concentration masks should be adjusted for patients with high peak inspiratory flows. Flow rate is the only variable that is prescribed with nasal cannulas, and an accurate prescription of flow rate is essential as hypercapnic respiratory failure may occur. ${ }^{4}$ Oxygen for delivery by nasal cannula is often prescribed by 
concentration, with the assumption that an inspired oxygen concentration of $24 \%$ equates to $2 \mathrm{l} / \mathrm{min}$; concentrations of $24 \%-35 \%$ with $2 \mathrm{l} / \mathrm{min}$ have been described. $^{5}$

The prescription of oxygen is complex, and a drug Kardex does not accommodate the precise details required for the variety of delivery devices. This was clearly shown in the second audit, where the accuracy of the prescription was greater with the chart than with the drug Kardex. We have shown that a specific prescription chart for oxygen improved clinical practice in our specialist medical respiratory centre, and we recommend the use of such a chart.

Contributors: MED designed the study, analysed and interpreted the results, and wrote the paper. FK and $\mathrm{AD}$ analysed and interpreted the data. JCGS designed the study and the chart. AKW and CSH critically revised the paper. RMcLN designed the study and the chart and critically revised the paper.

Competing interests: None declared.

1 British National Formulary 1999;37:153.

2 Bateman NT, Leach RM. ABC of oxygen. Acute oxygen therapy. BMJ 1998;317:798-801.

3 Small D, Duha A, Wieskopf B, Dajczman E, Laporta D, Kreisman H, et al. Uses and misuses of oxygen in hospitalised patients. Am J Med 1992;92:591-5.
The North West Lung Centre Oxygen Prescription Chart

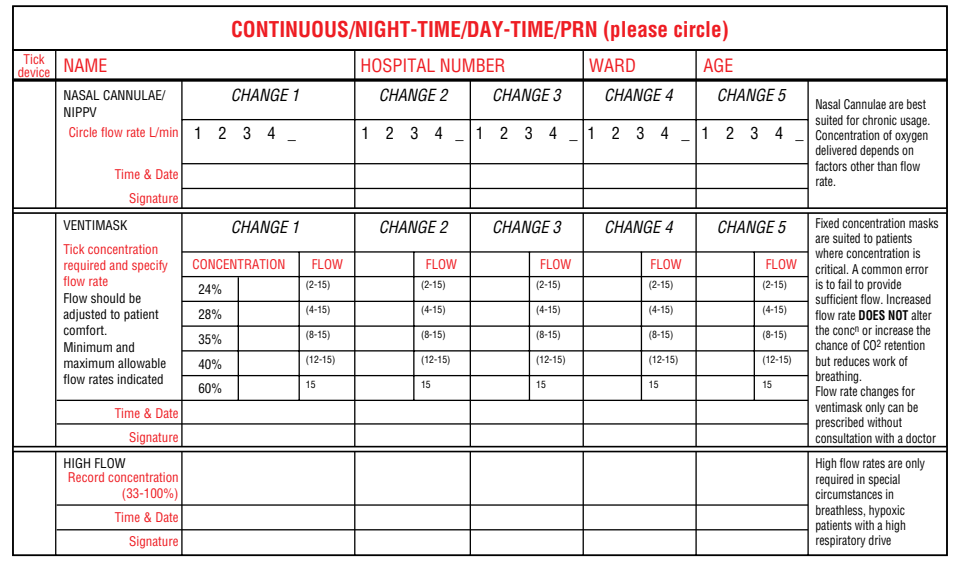

Prescription chart for oxygen introduced after first audit

4 Davies RJO, Hopkin JM. Nasal oxygen in exacerbations of ventilatory failure: an underappreciated risk. BMJ 1989;299:43-4

5 Bazuaye EA, Stone TN, Corris PA, Gibson GJ. Variabilty of inspired oxygen concentration with nasal cannulas. Thorax 1992;47:609-11.

(Accepted 11 May 2000)

\title{
Refused and granted requests for euthanasia and assisted suicide in the Netherlands: interview study with structured questionnaire
}

\author{
Ilinka Haverkate, Bregje D Onwuteaka-Philipsen, Agnes van der Heide, Piet J Kostense, \\ Gerrit van der Wal, Paul J van der Maas
}

In 1995, physicians in the Netherlands received 9700 explicit requests for euthanasia or physician assisted suicide, of which $37 \%$ were granted and carried out. ${ }^{1}$ Among the remaining requests, about half were refused by the physician; in the rest of the cases either the physician's promise of help could be effected, or the patient withdrew the request. ${ }^{2}$ Knowledge of specific characteristics of refused and granted requests for euthanasia or physician assisted suicide may give insight into physicians' decision making and into the role of criteria for prudent practice. We therefore compared the characteristics of refused and granted requests.

\section{Subjects, methods, and results}

In 1995 and 1996, 405 Dutch physicians, randomly sampled nationwide and stratified by specialty and region, were interviewed by over 30 specifically trained and experienced physicians using a structured questionnaire. The response rate was $89 \%$. Euthanasia was defined as the administration of drugs with the explicit intention of ending the patient's life, at the patient's explicit request. Assisted suicide was defined as the prescribing or supplying of drugs with the explicit intention of enabling the patient to end his or the patient died before a decision had been reached or her own life. All physicians were asked to describe their most recent case of a granted request (134 physicians had had such a case) and their most recent case of a refused request (148 physicians had had such a case).

Patients whose requests were refused, compared with patients whose requests were granted, were more often female and aged over 80; were less likely to have cancer; were more likely to have depression as a predominant complaint; were more likely to have a remaining life span of over six months; were less likely to have made a highly explicit request; were less likely to be competent; were less likely to be suffering utterly "hopelessly and unbearably," and were more likely to have access to alternatives for treatment (table).

In both the refused and the granted requests "avoiding loss of dignity" (42\% (95\% confidence interval $31.6 \%$ to $52.4 \%)$ and $56 \%(46.3 \%$ to $66.2 \%)$ respectively) and "unbearable or hopeless suffering" $(39 \%(29.0 \%$ to $48.8 \%)$ and $74 \%(64.9 \%$ to $82.6 \%))$ were most often mentioned as the patient's reason for requesting euthanasia or physican assisted suicide. Only two reasons were mentioned more often in refused requests than in granted requests: "weariness of life" $(40 \%(29.8 \%$ to $50.5 \%)$ and $18 \%(10.2 \%$ to $25.5 \%$ ) respectively) and "not wanting to become

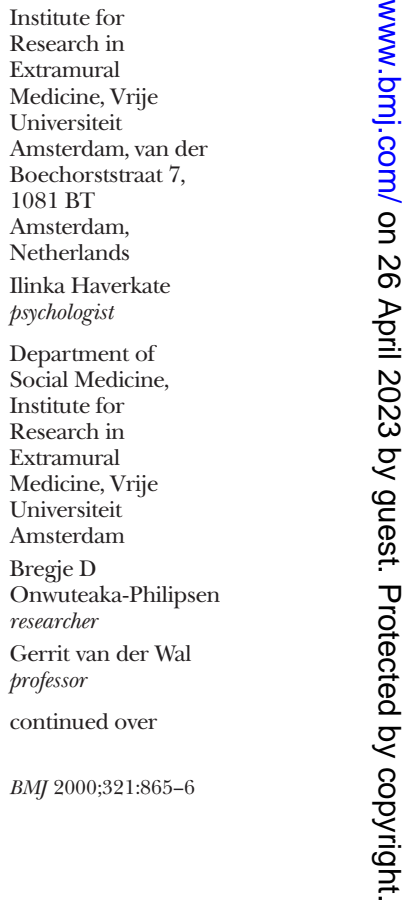

BMJ VOLUME 3217 OCTOBER 2000 bmj.com 